\title{
CORD BLOOD TRANSPLANTS: PERINATAL STEM CELLS IN CLINICAL PRACTICE
}

Richard L. Haspel

Beth Israel Deaconess Medical Center, Department of Pathology, 330 Brookline Avenue, Yamins 309, Boston, MA 02215

Karen K. Ballen

Massachusetts General Hospital, Division of Hematology/Oncology,

Department of Medicine, Boston, MA 02215

\section{INTRODUCTION}

Hematopoietic stem cells (HSCs) are currently the only perinatal stem cells routinely used for treatment of patients. This chapter reviews the collection, processing, and utility of cord blood (CB) in comparison to adult HSC sources. Also addressed are active areas of research including double $\mathrm{CB}$ transplants.

\section{HEMATOPOIETIC STEM CELL TRANSPLANTS: ADULT DONOR COLLECTION}

In a myeloablative hematopoietic stem cell transplant (HSCT), patients with hematologic malignancies are given high doses of chemotherapy and/or irradiation to eradicate the tumor. In the process, however, the patient's native marrow is destroyed requiring replacement by a source of HSCs. The HSCs can either be collected from the patient prior to transplant (autologous) or from a related or unrelated donor (allogeneic).

Bone marrow (BM) was the donor source for the first allogeneic HSCT performed in 1957 and is currently used in $\sim 25 \%$ of adult transplants in the United States

Perinatal Stem Cells. Edited by C. L. Cetrulo, K. J. Cetrulo, and C. L. Cetrulo, Jr. Copyright (C) 2009 Wiley-Blackwell 
[Appelbaum, 2007; CIBMTR, 2007]. Typically, BM is collected from the iliac crest in an operating room with the patient under general anesthesia. Collection goals are typically $2 \times 10^{8}$ total nucleated cells per kilogram (recipient weight) that can lead to $>1 \mathrm{~L}$ of product being collected. The dose of actual HSCs collected from BM, as measured by CD34+ cell content, is $\sim 2-3 \times 10^{6} / \mathrm{kg}$ [Bensinger, 2001; Blaise, 2000; Couban, 2002; Schmitz, 2002].

In the United States, collection of HSCs from peripheral blood has overtaken BM as the primary graft source in adult patients. Treating donors with growth factors, for example, granulocyte colony stimulating factor (GCSF) for 4 days leads to mobilization of CD34+ HSCs from the BM into the peripheral blood. These cells can then be collected by apheresis. During apheresis, donor blood is separated by centrifugation to allow selective removal of the cell layer containing the HSCs. The remaining white blood cells, red cells, platelets, and plasma are returned to the patient. In a single apheresis session, $\sim 10-20 \mathrm{~L}$ of the donor's blood is processed and only one or two sessions are usually required to reach the typical minimum target dose of $2 \times 10^{6} \mathrm{CD} 34+$ cells $/ \mathrm{kg}$. These collections yield higher numbers of CD34+ HSCs $\left(5-10 \times 10^{6} \mathrm{CD} 34+\right.$ cells $\left./ \mathrm{kg}\right)$, as well as T cells compared to bone marrow [Bensinger, 2001; Blaise, 2000; Couban, 2002; Schmitz, 2002].

In general, both BM and peripheral blood stem cells (PBSC) collection are well tolerated, but there are side effects. The BM donors typically have pain from the procedure and may have nausea and vomiting from the general anesthesia. The PBSC donors can experience bone pain from the GCSF injections, as well as symptoms of hypocalcemia from the citrate anticoagulant infused during the apheresis procedure.

One of the largest studies of collection-related side effects compared $166 \mathrm{BM}$ and 163 PBSC donors who were part of a randomized trial [Favre, 2003]. The rates of adverse events were similar (57\% for BM vs. $65 \%$ for PBSC donors). Serious adverse events occurred in $1 \%$ of BM donors and 7\% of PBSC donors. The BM donors most often had harvestrelated complaints while PBSC donors complained of side effects from GCSF. The BM donors required longer hospital stays (median of 2 vs. 0 days) and had more days of restricted activity (median of 6 vs. 2 days).

This study and others confirm that while donations are usually safe, they are not risk-free [Bredeson, 2004; Favre, 2003; Heldal, 2002; Rowley, 2001]. Overall, complication rates are similar, but BM donors may take longer to recover and often require overnight hospital stays. A recent review cited an estimated 1 in 10,000 risk of dying from a BM harvest with the same or possibly less risk from a PBSC collection [Horowitz, 2005].

\section{HEMATOPOIETIC STEM CELL TRANSPLANTS: ADULT DONOR TESTING}

Extensive testing of adult allogeneic donors is performed prior to collection. Aside from evaluating the donor's overall health to ensure they can tolerate the collection procedure, the FDA (21CFR Part 1271) and the Foundation for Accreditation of Cellular Therapy (FACT standards, C6.3) require testing and screening for infectious diseases including human immunodeficiency virus (HIV), hepatitis $\mathrm{C}$ virus (HCV), human T-lymphotropic virus (HTLV), hepatitis B virus (HBV), and syphilis. This testing must be performed within 30 days of collection. In addition, if a related donor is not available, donors are identified through registries, for example, the National Marrow Donor Program (NMDP) and HLA typing must be confirmed.

Until recently, allogeneic transplants were matched at HLA-A, B and DR (i.e., a 6/6 match). Matching was typically low-resolution/serological at class I (A, B) 
and high-resolution/allele level at class II (DR). Currently, most BM and PBSC transplant are matched at high resolution for classes I and II. In addition, for unrelated donor transplants, allele-level matching is also preferred at HLA-C and DQ leading to the ideal of a 10/10 match [Kogler, 2005].

The identification of a donor and the additional testing listed above takes considerable time. Using adult stem cell sources, $\sim 25 \%$ of the time, a patient has a first-degree relative who can provide a source of allogeneic stem cells. If there is no relative, $\sim 80 \%$ of the time a donor is found through NMDP for Caucasian patients. Minority patients have a lower probability of finding a match (e.g., $60 \%$ chance for African-Americans). The unfortunate fact is that only $30 \%$ of patients actually make it to transplant as they can be very ill and it takes considerable time to identify, test, and prepare a donor for collection [Government Accounting Office, 2002].

\section{HEMATOPOIETIC STEM CELL TRANSPLANTS: RECIPIENT ISSUES}

In North America, the majority of allogeneic transplants are performed for hematologic malignancies, most often acute and chronic leukemia. The most common cause of death from allogeneic transplant, $\sim 40 \%$, is relapse [CIBMTR, 2007]. As such, disease-free survival (DFS) is an important outcome measure.

In regard to short-term morbidity and mortality, there can be significant toxicity from the chemotherapy and/or radiation. Hemorrhagic cystitis, mucositis, cardiac and renal toxicity are all concerns. In addition, it can take significant time for the donor stem cells to engraft. Typical outcome measures are time to absolute neutrophil count (ANC) $>500$, platelets $>20,000$ (short-term engraftment) and platelets $>50,000$ or 100,000 (long-term platelet engraftment). Time to engraftment is correlated with stem cell dose and can range for ANC $>500$ from $<2$ weeks with PBSC to over a month with CB [Bensinger, 2001; Blaise, 2000; Couban, 2002; Eapen, 2007; Laughlin, 2004; Rocha, 2001, 2004; Schmitz, 2002; Takahashi, 2004, 2007]. Although patients can be supported with red blood cell and platelet transfusions, they are at increased risk of infection and often have to be placed on antibacterial and antifungal medications. Given these early complications, transplant-related mortality (TRM), often defined as death prior to day 100 post-transplant, is another important outcome measure.

Another source of morbidity and mortality is graft-versus-host-disease (GVHD). Upon engraftment, donor immune cells may attack the recipient as foreign. Skin is most commonly involved although any organ can be affected. Aside from complications due to the GVHD itself, patients are often placed on immunosuppressive regimens that put them at greater risk for infection. The GVHD accounts for $\sim 15 \%$ of mortality from allogeneic stem cell transplants [CIBMTR, 2007]. Due to differences in biologic mechanisms, GVHD is typically separated into symptoms occurring in the first 100 days of transplant (acute GVHD) and those occurring post-100 days (chronic GVHD).

Given the significant regimen-related toxicity, many patients are not candidates for ablative conditioning. For this reason, non-myeloablative/reduced intensity conditioning (RIC) regimens are also utilized. In this setting, the goal of the chemotherapy is not to destroy to the tumor, but to create enough immunosuppression to allow engraftment of the donor HSCs. Once the HSCs engraft, the donor immune system will attack the tumor. This phenomenon, known as the graft-versus-leukemia/lymphoma effect, was first identified in patients with chronic myelogenous leukemia (CML). In these patients, improved survival was correlated with GVHD suggesting that the donor immune system was attacking the tumor, as well as the recipient's normal tissue. Consistent with this model, further studies demonstrated 
that infusion of donor lymphocytes (DLI) can help treat leukemic relapses [Kolb, 1990]. The DLI is now a standard treatment for relapses posttransplant of several hematologic malignancies, but is not a possibility with cord blood transplant [Chen, 2007; Daly, 2003; Dey, 2003].

\section{COLLECTION AND PROCESSING OF CORD BLOOD UNITS}

Unlike BM and PBSC for HSCT, a major advantage of using CB is that there is no potential for harm to the donor (mother or child). As such, almost any normal pregnancy can produce a potential cord blood unit (CBU) for transplant. In addition, all required testing is done "up front" avoiding delays for transplant. One study from the University of Minnesota found that the median time of donor availability was 13.5 days for $\mathrm{CB}$ and 49 days for BM, an important difference to patients with aggressive leukemias [Dalle, 2004].

Cord blood units can be collected either pre- or postdelivery of the placenta. The umbilical vein is cannulated and $\sim 100 \mathrm{cc}$ of blood is collected in a bag containing citrate anticoagulant. Products are typically frozen in 10\% dimethyl sulfotide (DMSO). Many centers also plasma and red cell reduce products prior to cryopreservation. This process leads to smaller volumes allowing for easier storage and reduction of cellular debris upon thawing.

The CBU collection and processing protocols are under investigational new drug (IND) status and are not standardized. Although national and international accrediting agencies, for example, FACT and AABB, provide oversight, there are still differences in collection center procedures. Recently, as a step toward product licensure, the Food and Drug Administration (FDA) has drafted a guidance document for CBUs intended for HSC transplant [FDA, 2006]. The recommendations are similar to those required for other minimally manipulated stem cell products (21CFR Part 1271) including testing and screening for HIV, HTLV, HBV, HCV, syphilis, and cytomegalovirus to determine communicable disease risk. The testing should be performed on the mother and must occur within 7 days of collection. Additional recommended testing and screening includes analysis for hemoglobinopathies and HLA and blood group typing. Although some European centers perform follow-up testing of the donors 6 months after product collection or shortly before product release to determine if there has been any significant change in the donor health, similar requirements are not in the draft guidance document.

The FDA has also proposed guidelines for validating processing procedures to confirm purity and potency. Acceptance criteria include $>=5 \times 10^{8}$ TNC with $>=85 \%$ viable and $>=1.25 \times 10^{6} \mathrm{CD} 34+$ cells per CBU. In regard to cyropreservation, a validated freeze-thaw procedure must allow recovery of $70 \%$ of viable nucleated cells. As these criteria demonstrate, the total nucleated cell (TNC) and CD34+ cell dose from a CBU is approximately 10 -fold lower than the dose that can be obtained from a BM collection [Eapen, 2007; Laughlin, 2004; Rocha, 2001, 2004; Takahashi, 2004, 2007].

Postthaw processing is not discussed in the FDA guidance document and there is variation between centers. Since early cord blood transplants were performed on children with non-red cell reduced CBUs, products were washed after thawing to remove the potentially toxic effects of DMSO or cellular debris. Washing, however, may also lower the cell dose [Laroche, 2005]. Chow et al. found delays in engraftment, presumably due to differences in cell dose, in washed versus nonwashed products [Chow, 2007]. Both neutrophil (ANC >500: 20 days vs. 27 days, $p<0.02$ ) and platelet engraftment ( $>20,000: 47$ vs. 54 days, $p=0.0003$ ) were faster with nonwashed cord blood. Their study, as well as others, also demonstrates that unwashed products can be safely infused without significant adverse events [Chow, 2007; Hahn, 2003; Nagamura-Inoue, 2003]. 
Although there are no results from randomized trials, some centers infuse CBUs after thawing without a wash step.

\section{BONE MARROW VERSUS SINGLE CORD BLOOD: PEDIATRIC}

The first cord blood transplant (CBT) was performed in 1989 on a child in France with Fanconi's anemia [Gluckman, 1989]. He received a cryopreserved CBU from a female sibling. Since that time, thousands of unrelated CBTs have been performed. Due to the concern over low cell dose, the majority of early CBTs were performed in children. Observational studies comparing CB with adult hematopoietic stem cell sources have demonstrated both the advantages and disadvantages of these transplants (Tables I.1, I.2).

The largest comparison study in children looked at 785 patients $(<=16$ years old) with acute leukemia; 503 received cord blood and 283 received bone marrow [Eapen, 2007]. Only $7 \%$ of CBUs were a $6 / 6$ match with the recipient ( $40 \%$ were a single-antigen and $53 \%$ were a two-antigen mismatch). In addition, $41 \%$ of the bone marrow transplant (BMT) patients were allele-level matched at both class I and class II. The CBUs were obtained at a median of 10-16 months while BM was obtained at a median of 20-23 months. As will be the case for all the cord blood studies reviewed below, $\mathrm{CB}$ recipients received an approximately 10 -fold lower TNC dose.

Time to engraftment was delayed in recipients of cord blood. Recovery of ANC $>500$ and platelets $>20,000$ occurred at a median of 25 and 59 days for CBU recipients compared to 19 and 27 days for BM recipients. In addition, 19\% of CBT compared to 3\% of BMT patients had primary graft failure. Although 100-day transplant related mortality (TRM) was greater in the patients receiving mismatched cord blood, rates of acute and chronic GVHD, and 5-year leukemia-free survival were similar when compared to patients receiving allele-matched BM. Fully matched CB recipients had improved survival compared to unrelated $\mathrm{BM}$ recipients.

Another large study in children compared 99 myeloablative CBT with 262 unrelated BM transplants for patients, ages 2-12, with acute leukemia [Rocha, 2001]. Overall results were comparable to the above study. Only $8 \%$ of the CBUs were $6 / 6$ matches with the recipient ( $43 \%$ were $5 / 6$ and $41 \%$ were $4 / 6$ matches) compared with $80 \%$ of the $\mathrm{BM}$ products and the time from complete remission (CR) to transplant was faster in the patients receiving CBUs (84 days vs. 113 days). Neutrophil engraftment was also delayed in the CBU recipients ( 32 days vs. 18 days) as was platelet recovery ( $>20,000: 81$ days vs. 29 days). Only $4 \%$ of BMT compared to $20 \%$ of CBT patients had not recovered their

TABLE I.1. Comparative Studies of Unrelated Myeloablative Single CB versus BM Transplant in Children with Leukemia ${ }^{a}$

\begin{tabular}{|c|c|c|c|c|c|c|c|}
\hline \multirow[b]{2}{*}{ Study } & \multirow[b]{2}{*}{$\begin{array}{c}\mathrm{N} \\
(\mathrm{CB} / \mathrm{BM})\end{array}$} & \multirow[b]{2}{*}{$\begin{array}{c}\% \text { DFS (follow-up in } \\
\text { months) }\end{array}$} & \multicolumn{3}{|c|}{ Engraftment } & \multicolumn{2}{|c|}{ GVHD (\%) } \\
\hline & & & $\begin{array}{l}\text { ANC } \\
\text { (day) }\end{array}$ & $\begin{array}{l}\text { Plts } \\
\text { (day) }\end{array}$ & $\begin{array}{c}\text { Primary Failure } \\
(\%)\end{array}$ & $\begin{array}{l}\text { Acute } \\
\text { II-IV }\end{array}$ & Chronic \\
\hline Rocha, 2001 & $99 / 262$ & $31 / 43(19 / 30)$ & $32 / 18$ & $81 / 29$ & $20 / 4$ & $35 / 58$ & $12 / 43$ \\
\hline Eapen, 2007 & $503 / 282$ & $33 / 38^{b}(44 / 60)$ & $27 / 19$ & $59 / 25$ & $19 / 3^{b}$ & $41 / 46^{b}$ & $15 / 32^{b}$ \\
\hline
\end{tabular}

${ }^{a}$ Abbreviations: DFS = disease-free survival; ANC $=$ absolute neutrophil count $>500$; Plts $=$ platelets $>20,000 ;$ GVHD $=$ graft versus host disease.

${ }^{b}$ Two HLA antigen-mismatch CB/HLA allele-matched BM. 
TABLE I.2. Comparative Studies of Unrelated Myeloablative Single CB versus $6 / 6$ Matched BM Transplant in Adults ${ }^{a}$

\begin{tabular}{|c|c|c|c|c|c|c|c|}
\hline \multirow[b]{2}{*}{ Study } & \multirow[b]{2}{*}{$\begin{array}{c}\mathrm{N} \\
(\mathrm{CB} / \mathrm{BM})\end{array}$} & \multirow[b]{2}{*}{$\begin{array}{c}\% \text { DFS (follow-up in } \\
\text { months) }\end{array}$} & \multicolumn{3}{|c|}{ Engraftment } & \multicolumn{2}{|c|}{ GVHD (\%) } \\
\hline & & & $\begin{array}{l}\text { ANC } \\
\text { (day) }\end{array}$ & $\begin{array}{l}\text { Plts } \\
\text { (day) }\end{array}$ & $\begin{array}{c}\text { Primary } \\
\text { Failure }(\%)\end{array}$ & $\begin{array}{l}\text { Acute } \\
\text { II-IV }\end{array}$ & Chronic \\
\hline Laughlin, 2004 & $150 / 367$ & $23 / 33(40 / 48)$ & $27 / 18$ & $60 / 29$ & $30 / 10^{b}$ & $41 / 48$ & $51 / 35^{c}$ \\
\hline Rocha, 2004 & $98 / 584$ & $33 / 38(27 / 24)$ & $26 / 19$ & $\mathrm{~N} / \mathrm{S}$ & $20 / 7$ & $26 / 39$ & $30 / 46$ \\
\hline Takahashi, $2004^{d}$ & $68 / 45$ & $74 / 44(26 / 59)$ & $22 / 18$ & $40 / 25$ & $8 / 0$ & $50 / 67$ & $78 / 74^{c}$ \\
\hline $\begin{array}{l}\text { Takahashi } \\
\text { related, } 2007^{d}\end{array}$ & $100 / 71$ & $70 / 60(22 / 32)$ & $22 / 17$ & $40 / 22$ & $5 / 0$ & $55 / 60$ & $89 / 90^{c}$ \\
\hline
\end{tabular}

${ }^{a}$ Abbreviations (also see Table I.1): N/S = not stated.

${ }^{b}$ Approximate.

${ }^{c}$ Extensive chronic GVHD greater in patients who received BM.

${ }^{d}$ Takahashi, 2004: results include 6 patients with 5/6 matched adult donors. Takahashi, 2007: results include 11 patients with 5/6, 6 patients with 4/6 matched. Adult donors and 16 related peripheral blood stem cell transplants.

neutrophil counts by day 60 . In contrast to the above study, perhaps due to the lack of allelelevel typing of BM, CBU recipients also had significantly less acute and chronic GVHD. When adjusted for prognostic factors, CBU recipients had an increased risk of 100-day TRM, but overall post-100-day survival was equivalent.

Although the majority of CBTs are performed for hematologic diseases, there also has been success treating metabolic disease in children. For example, Staba et al. treated 20 children with Hurler's disease with single cord blood transplant [Staba, 2004]. Hurler's disease is a mucopolysaccharidosis that leads to neurologic disease and death. Overall survival and rates of GVHD appeared better than historical reports of BMT for this condition. Improvements in neurological development were also demonstrated. Other nonmalignant diseases including thalassemia and X-linked adrenoleukodystrophy also have been treated with CBT [Beam, 2007; Jaing, 2005].

\section{BONE MARROW VERSUS CORD BLOOD: ADULTS}

Given the success in pediatric patients, $\sim 50 \%$ of CBTs are now performed in adults [Netcord, 2007]. Similar to the pediatric literature, there are also observational studies in adults treated with ablative regimens comparing BM with CB (Table I.2). Rocha et al. compared 584 adult patients receiving unrelated donor BM to 98 patients receiving unrelated CBUs for acute leukemia [Rocha, 2004]. Only $6 \%$ of CBUs were a $6 / 6$ match (cf. $100 \%$ of $\mathrm{BM}$ ), $39 \%$ were a $4 / 6$ match and $4 \%$ were a $3 / 6$ match. Median time to neutrophil engraftment was delayed (19 days for BM and 26 days for $\mathrm{CB}$ ) and graft failure occurred in $7 \%$ of patients in the BM group and $20 \%$ in the $\mathrm{CB}$ group $(p<0.001)$. The rate of acute GVHD (aGVHD) was significantly lower in the CB group with a similar trend for chronic GVHD (cGVHD). There were no significant differences in TRM, relapse, or disease free survival.

Laughlin et al. compared 150 single unrelated cord blood transplants to 450 unrelated bone marrow transplants for acute leukemia [Laughlin, 2004]. While 82\% of BMs were $6 / 6$ matches (the rest were $5 / 6$ matches), $77 \%$ of CBUs were $4 / 6$ matches with the rest being $5 / 6$ matches. Both neutrophil and platelet recovery were delayed. The time to an ANC $>500$ 
occurred at a median of 27 days for CBT versus 18-20 days for BMT patients and the time to platelets $>20,000$ occurred at median of 60 versus 29 days. There was also an increase in graft failure with $\mathrm{CB}$ when compared to $\mathrm{BM}$, but this only reached statistical significance when measured against $6 / 6$ matched marrow $(p<0.01)$.

The rate of acute GVHD in the CB recipients was similar to that of patients who received $6 / 6$ matched bone marrow and better than that of patients who received 5/6 BM. While there was significantly more chronic GVHD in CB compared to matched BM recipients, the rate of extensive chronic GVHD was lower in $\mathrm{CB}$ recipients when compared to all $\mathrm{BM}$ recipients. In regard to TRM and overall mortality, $\mathrm{CB}$ was essentially equivalent to 5/6 matched marrow, but worse than $6 / 6$ matched marrow $(\mathrm{OR}=1.53,95 \% \mathrm{CI}=1.21-1.94)$.

A third retrospective study from Japan included adults ( $>16$ years old) with leukemia, myelodysplastic syndrome, or non-Hodgkin's lymphoma [Takahashi, 2004]. All patients received a myeloablative conditioning regimen followed by infusion of unrelated CB $(n=68)$ or unrelated BM $(n=45)$. None of the CB units were a $6 / 6$ match with the recipient and $22 \%$ were a $3 / 6$ match. In contrast, $87 \%$ of the $\mathrm{BM}$ was a $6 / 6$ match with the remainder being a 5/6 match with the recipient. The duration of the donor search was significantly shorter for CBU recipients (3 months vs. 11 months) with a similar trend for time from diagnosis to transplant (17 months vs. 20 months).

Neutrophil engraftment occurred at day 22 for CB and day 18 for BM recipients and short- and long-term platelet engraftment was also significantly delayed ( $>20,000: 40$ vs. 25 days; $>50,000$ : 48 vs. 28 days). The graft failure rate was also higher with CBT (8\% vs. 0\%). In regard to GVHD, the rate of grade III/IV acute GVHD was significantly higher with BM transplant with a similar trend for extensive chronic GVHD. The 1-year TRM (9\% vs. $29 \%$ ) and 2-year disease-free survival (74\% vs. $44 \%$ ) was significantly better with CB transplant.

A follow-up study from Japan included patients aged 16 years or older with a variety of hematologic malignancies who received a myeloablative unrelated CB transplant $(n=100)$, a related BM transplant $(n=55)$ or related PBSC transplant $(n=16)$ [Takahashi, 2007]. The majority of patients had acute or chronic leukemia and none of the $\mathrm{CB}$ units were a $6 / 6$ match compared to $76 \%$ of the BM. Additionally, $28 \%$ of the CBUs were a $3 / 6$ match. Likely due to better availability of related donors, the difference in time from diagnosis to transplant was shorter for BMT, but this did not reach statistical significance (17.5 months for CB vs. 15 months for BM, $p=0.3$ ). Similar to the above studies, both neutrophil (22 vs. 17 days) and short-term platelet engraftment ( $>20,000 ; 40$ days vs. 22.5 days) was delayed with CB compared to BM. There was also a significant delay in long-term platelet engraftment $(>50,000 ; 46$ vs. 27 days) and a slightly higher rate of graft failure rate (5\% vs. $0 \%$ ) in the CB group. The above engraftment issues may have led to the increase in hospital length of stay in recipients receiving CB (121 vs. 89 days, $p=0.1)$.

The rate of grade III/IV acute GVHD and extensive chronic GVHD was significantly lower with $\mathrm{CB}$ transplant. As a result, more BM recipients required steroid treatment for acute GVHD and had a slower taper of their immunosuppressive regimens. There were no significant differences in TRM, relapse or survival.

\section{CORD BLOOD TRANSPLANT: ADVANTAGES AND DISADVANTAGES}

Review of the above studies clearly demonstrates the advantages and disadvantages of single CBT. The CB allows faster time to transplant. In most studies in which it was measured, time from diagnosis or complete remission to transplant was months shorter than with 
an unrelated BM donor. As discussed above, this reflects the fact that all testing is done "up front" with CB and should allow more patients to obtain transplants.

Another advantage is that a less than perfect HLA match is adequate for CBT. The majority of units transplanted in the above studies were a $4 / 6$ match with the recipient. Some were even $3 / 6$ matches with all typing performed at the low-resolution level for class I. Even with this degree of mismatch, the rates of acute GVHD or extensive chronic GVHD were either the same or lower in the CBT patients. This increased flexibility with HLA matching will allow more individuals to be transplanted. Stevens et al. calculated, based on the ethnic distribution of donors and patients in New York City, that $<170,000$ units would be required to guarantee a minimum $5 / 6$ match for $80 \%$ of adult transplant candidates [Stevens, 2005]. While some studies indicate better HLA matching may lead to improved engraftment and survival, it is clear that CBU 4/6 matches, unlike for BM and PBSC, are acceptable and can lead to good results with no increase in GVHD [Eapen, 2007; Kamani, 2008]. Further research is needed on the effect of HLA mismatch and high- versus low-resolution HLA matching on CBT outcomes [Delaney, 2007].

The above studies demonstrate that the major disadvantage of CB is the low-cell dose. In all studies, TNC dose was approximately 10 -fold lower in the CBUs and this likely led to the delays in engraftment, increased rates of primary graft failure, as well as increases in TRM. Several groups have directly correlated infused cell dose to engraftment and TRM [Gluckman, 2000; Wagner, 2002].

Despite worse engraftment with CBT, disease-free survival generally showed no difference when compared to BM. Perhaps, any increase in early mortality is compensated by the decrease in late mortality due to GVHD. The study by Laughlin et al., in which CBT was equivalent to one-antigen mismatched marrow, but worse than fully matched $\mathrm{BM}$, is an exception among the above studies [Laughlin, 2004]. In this study, however, transplants were performed in an earlier time period when only the sickest adult patients with no other options were transplanted with CB [Sanz, 2004].

Another exception is the unrelated transplant trial by Takahashi et al. [Takahashi, 2004]. The authors found that $\mathrm{CB}$ recipients did significantly better than unrelated BM recipients. This study involved only a single institution and perhaps there were differences in care or patient makeup that led to this result. For example, Japan has a more homogeneous population than Europe and North America and HLA disparity may have less impact on outcomes. Note that the same group did not find this difference in their study of related BM donors. These results might be explained by differences in GVHD related deaths in the two studies. With unrelated BM transplants, 10 of the 24 BM recipients died of GVHD (42\%) as compared to none of the 16 expired CB recipients. In the study with related BM donors, 26 in the BM group and 25 in the CB group died. In both groups, GVHD was the cause of death for $12 \%$ of patients. The sharp drop in GVHD related deaths in the BM recipients may reflect better (allele-level) HLA matching when there is a related BM donor.

\section{DOUBLE CORD BLOOD TRANSPLANTS: ABLATIVE REGIMENS}

Prior studies indicate that cell dose is an important factor for engraftment and survival in the setting of CBT. As such, several groups have attempted infusion of two cord blood units to overcome this limitation (Table I.3).

In 2005, Barker et al. published the largest study of myeloablative DCBTs to date [Barker, 2005]. Twenty-three patients aged 13-53 with leukemia received myeloablative conditioning followed by infusion of two CBUs (median TNC dose of $3.5 \times 10^{7} / \mathrm{kg}$ ). 
TABLE I.3. Double Cord Blood Transplant (DCBT) Studies ${ }^{a}$

\begin{tabular}{|c|c|c|c|c|c|c|c|c|}
\hline \multirow[b]{2}{*}{ Study } & \multirow[b]{2}{*}{ N-DCBT } & \multirow[b]{2}{*}{ Diagnosis } & \multirow[b]{2}{*}{$\begin{array}{c}\% \text { DFS } \\
\text { (follow-up } \\
\text { in months) }\end{array}$} & \multicolumn{3}{|c|}{ Engraftment } & \multicolumn{2}{|c|}{ GVHD (\%) } \\
\hline & & & & $\begin{array}{l}\text { ANC } \\
\text { (day) }\end{array}$ & $\begin{array}{l}\text { Plts } \\
\text { (day) }\end{array}$ & $\begin{array}{l}1^{\circ} \\
\text { Failure } \\
(\%)\end{array}$ & $\begin{array}{l}\text { Acute } \\
\text { II-IV }\end{array}$ & Chronic \\
\hline $\begin{array}{l}\text { Barker, } \\
2005\end{array}$ & 23 & ALL, AML, CML & $57(10)$ & 23 & $\mathrm{~N} / \mathrm{S}$ & 0 & 65 & 23 \\
\hline $\begin{array}{l}\text { Brunstein, } \\
\text { 2007, RIC }\end{array}$ & 110 & $\begin{array}{l}\text { High-risk heme } \\
\text { malignancy }\end{array}$ & 38 (19) & 12 & $\mathrm{~N} / \mathrm{S}$ & 6 & 59 & 23 \\
\hline $\begin{array}{l}\text { Ballen, } \\
2007 \text { RIC }\end{array}$ & 21 & $\begin{array}{l}\text { AML, ALL, NHL, } \\
\text { CLL, HD, MDS, } \\
\text { AA }\end{array}$ & $55(18)$ & 20 & 41 & 10 & 40 & 31 \\
\hline $\begin{array}{l}\text { Cutler, } 2007 \\
\text { RIC }\end{array}$ & 27 & $\begin{array}{l}\text { AML, ALL, NHL, } \\
\text { CLL, HD, MDS, } \\
\text { CML }\end{array}$ & $54(15)$ & 21 & 42 & 0 & 11 & 7 \\
\hline $\begin{array}{l}\text { Majhail, } \\
2006 \text { RIC }^{a}\end{array}$ & 9 & $\mathrm{HL}$ & $25(17)$ & 10 & $\mathrm{~N} / \mathrm{S}$ & 0 & 33 (III/IV) & 11 \\
\hline
\end{tabular}

${ }^{a}$ Abbreviations (also see Table I.1): RIC = reduced intensity conditioning; AML = acute myeloid leukemia; ALL = acute lymphocytic leukemia; $\mathrm{CLL}=$ chronic lymphocytic leukemia; $\mathrm{CML}=$ chronic myelogenous leukemia, $\mathrm{NHL}=$ non-Hodgkin's lymphoma; $\mathrm{HD}=$ Hodgkin's disease; $\mathrm{MDS}=$ myelodysplastic syndrome, $\mathrm{AA}=$ aplastic anemia.

${ }^{b}$ Outcomes also reflect several single CB transplants (Majhail: 2, Brunstein: 17).

Most patients received 4 or 5/6 matched units with only two receiving a 6/6 matched CBU. All the units were a minimum $4 / 6$ match with each other. The median time to neutrophil engraftment was 23 days (range: 15-41), which is slightly better than the times reported in most retrospective studies of myeloablative single cord blood transplants. While there was no graft failure, median time to platelets $>50,000$ was $\sim 90$ days. Thirteen percent of patients had severe grade III or IV acute GVHD and $23 \%$ of patients had chronic GVHD. The predicted 1-year survival was $57 \%$.

\section{DOUBLE CORD BLOOD TRANSPLANT: NON-MYELOABLATIVE REGIMENS}

A number of studies also have investigated the use of RIC regimens followed by DCBT (Table I.3). Although DLI cannot be administered following CBT, these studies have shown promise in regard to transplant outcomes. Considering at least $40 \%$ of allogeneic transplants utilize RIC regimens, CBT is an important option for patients without a matched adult donor [CIBMTR, 2007].

Brunstein et al. have reported the largest group of patients undergoing CBT with a RIC regimen [Brunstein, 2007]. Patients with hematologic malignancies were conditioned with fludarabine, cytoxan, and total body irradiation (TBI). Of 110 patients, $85 \%$ received two CBUs. Patient were selected to receive DCBT if the total TNC dose from a single unit was $<3 \times 10^{7} / \mathrm{kg}$. The TNC and CD34+ cell dose were statistically equivalent in recipients of one or two CBUs, but the CD3 + cell dose was two times higher in recipients of two units. The majority of units (64\%) were a $4 / 6$ HLA match with the recipient. In most DCBT patients, both units were a $4 / 6$ match $(43 \%)$ or one was a $4 / 6$ match and one was a $5 / 6$ match $(33 \%)$. Rates of neutrophil recovery were similar for single and DCBT recipients 
(94\% vs. 91\%). Neutrophil and platelet recovery $>50,000$ occurred at a median of 12 and 49 days, respectively, but data was not stratified for recipients of one or two CBUs. The overall rate of grades II-IV aGVHD was 59\% and of cGVHD it was 23\%. The DCBT patients had a statistically significant higher risk of aGVHD and a trend for better event-free survival. For all patients, 3-year survival was $45 \%$.

In our initial study of DCBT, we enrolled 21 adult DCBT recipients conditioned with fludarabine, melphalan, and anti-thymocyte globulin [Ballen, 2007]. The median combined TNC dose was $4 \times 10^{7}$ and $78 \%$ of the CBUs were a $4 / 6$ match with the recipient at the allele level for both class I and class II MHC. Median times of neutrophil and platelet $(>20,000)$ recovery were 20 and 41 days, respectively. Two patients had primary graft failure and one had a successful second DCBT using a different conditioning regimen. Only one patient developed severe (grade III) aGVHD and 5 of 16 evaluable patients (31\%) developed cGVHD with two having extensive disease. With a median follow up of 18 months, 2-year projected overall survival was 55\%. There were no significant associations between cell dose and degree of HLA match with GVHD or survival.

In a second study, we utilized the same conditioning regimen, but altered GVHD prophylaxis from cyclosporine and mycophenolate mofetil to sirolimus and tacrolimus, based on studies with this GVHD regimen in the related and unrelated donor setting [Cutler, 2004]. Twenty-seven patients with hematologic malignancies have been enrolled. Median times to engraftment were 21 days for ANC $>500$ and 42 days for platelets $>20,000$. All patients initially engrafted, although three were not platelet transfusion independent by day 100 and three had late graft failure. The rate of aGVHD was lower than in our previous trial $(11.1 \%)$ and only two patients developed cGVHD. Two-year disease-free survival was $54.4 \%$ [Cutler, 2007].

Only one small study utilizing a reduced intensity conditioning regimen has compared DCBT to BM transplants [Majhail, 2006b]. Patients either received a busulfan/fludarabine/ TBI or a cytoxan/fludarabine/TBI regimen. Twelve patients with Hodgkin's disease who received related $\mathrm{BM}$ were compared to nine patients who received unrelated $\mathrm{CB}$ (seven of these patients received two CBUs). While there were no graft failures, neutrophil recovery was delayed for the CB patients (10 vs. 7 days). There were no significant differences in rates of acute or chronic GVHD or progression-free survival. Although the authors suggest that $\mathrm{BM}$ is comparable to $\mathrm{CB}$, the numbers are too small to generalize this conclusion.

The above results are very promising and indicate there can still be significant graft versus tumor effect without high rates of GVHD in CBTs. Comparison of these trials is difficult due to variations in conditioning regimens [Barker, 2003].

\section{CHIMERISM}

In the setting of $\mathrm{HSC}$ transplant, chimerism refers to the percentage of donor versus recipient contribution to hematopoiesis. Typically, DNA fingerprinting techniques (i.e., amplification of short tandem repeat loci) are used to measure chimerism [Baron, 2005]. As opposed to standard transplants in which there is only one donor and one recipient, in the setting of DCBT there are two donors and the recipient. Initially, there was a concern that DCBT could lead to a "graft versus graft" effect and impair engraftment, but fortunately this does not appear to commonly occur. Although several early case reports demonstrated double chimerism post-transplant, subsequent studies indicate that generally only one CBU usually contributes to long-term engraftment [Barker, 2001; de Lima, 2002; Haspel, 2007]. 
The first DCBT study that analyzed chimerism was the myeloablative study of Barker et al. [Barker, 2005]. By day 21, 76\% of the patients showed hematopoiesis from only a single cord and this increase to $100 \%$ by day 100. In the study by Brunstein et al., for 81 patients with sustained chimerism that received a RIC regimen and DCBT, 57\% of patients had complete single donor chimerism at day $21,91 \%$ at day 100 and $100 \%$ at 1 year. The median percentage contribution of the predominant unit was 83\% (range: 8-100\%) at day 21 and 100\% (range: 34-100\%) after day 100 [Brunstein, 2007].

In our study of 38 patients, we reported three chimerism patterns [Haspel, 2007]. Group 1 consisted of patients in whom a single CBU contributed to $>=95 \%$ of hematopoiesis. In group 2, both $\mathrm{CB}$ units contributed to hematopoiesis. The third group consisted of patients with contributions of one CBU and the recipient. At day 30, 29\% of patients had single CBU hematopoiesis (group 1). As time progressed, patients transitioned to complete single unit chimerism with $50 \%$ in this group by day 60 and $66 \%$ in this group by day 100 (Fig. I.1).

Of the 16 patients followed over 1 year, 14 had chimerism from a single CBU by day 100 and all have retained complete single donor chimerism (five of these over 2 years and two over 3 years). The two other patients followed at least 1 year continue to have contributions of both CBU to hematopoiesis with 83 and $66 \%$ chimerism of the predominant CBU.

In our prior study of 21 patients, we also found a significantly different rate of chronic GVHD (0-100\%) when comparing patients with complete single donor chimerism at 6 weeks to those with either contribution of two CBUs or one CBU and the recipient to hematopoiesis [Ballen, 2007]. Chimerism pattern, however, does not appear to affect engraftment. Small numbers may limit the above results and further studies are needed to determine the effect of chimerism patterns on outcomes.

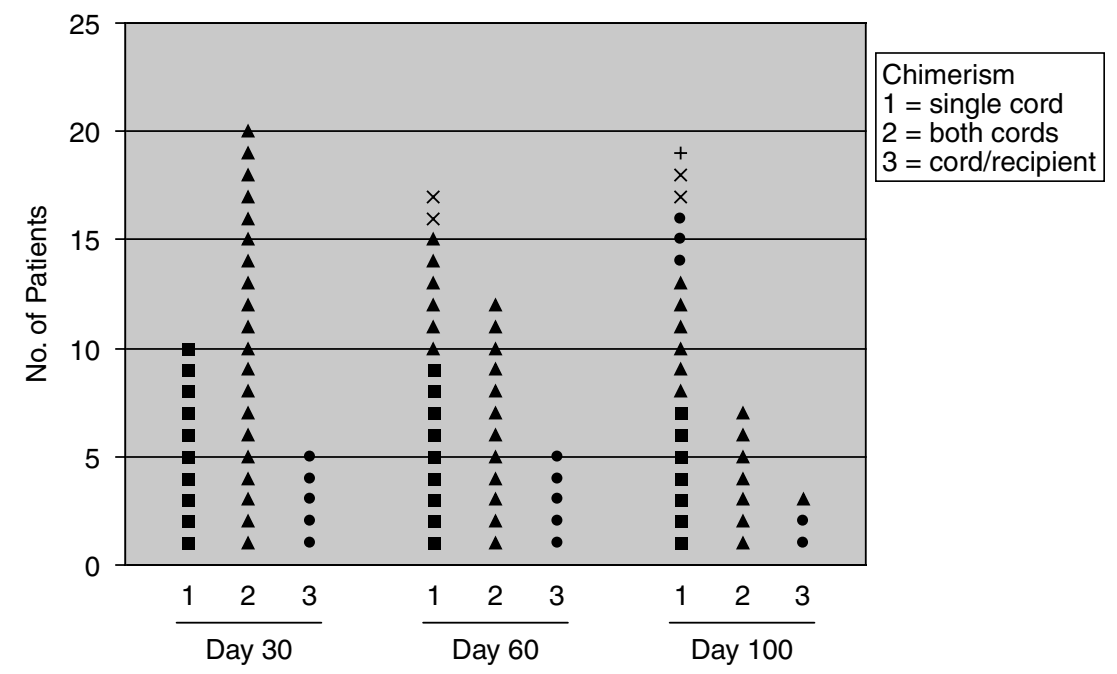

Figure I.1. Chimerism patterns. The numbers of patients with different chimerism patterns are shown at days 30,60, and 100. Individual patients are marked by shape based on chimerism at day 30 ( $\boldsymbol{\square}=$ group $1, \boldsymbol{\Lambda}=$ group $2, \bullet=$ group 3 ) or $\times=$ first chimerism result obtained at day $60,+=$ first chimerism result obtained at day 100 . [First published in Haspel, 2007.] 


\section{PREDICTING THE WINNER}

The DCBT offers a unique opportunity to study "competitive" transplants in humans. These studies may help us understand important and potentially modifiable preinfusion characteristics that may improve engraftment. The initial ablative Barker study found a link between a higher CD3 + cell dose and cord blood predominance [Barker, 2005]. The authors hypothesized an immunomodulatory effect, but this association disappeared as more patients were accrued [Majhail, 2006a]. In the Brunstein et al. study of 110 patients receiving a RIC regimen, neither TNC dose, $\mathrm{CD} 34+$ cell dose, $\mathrm{CD} 3+$ cell dose, $\mathrm{ABO}$ match, gender match or order of infusion predicted CBU predominance [Brunstein, 2007].

In our series of 38 patients, we also investigated preinfusion parameters (TNC dose, $\mathrm{CD} 34+$ cell dose, $\mathrm{ABO}$ match, gender match and age of the $\mathrm{CBU}$ ) for an effect on CBU predominance [Haspel, 2007]. We found that both a higher TNC and CD34+ cell dose $(p=0.06, p=0.03)$, as well as order of infusion $(p=0.03)$ were all independently associated with cord predominance. In $26 / 38$ transplants $(68 \%)$, the predominant cord blood unit was the first one infused.

What accounts for the differences in results? One possibility relates to recent findings on the nature of the hematopoietic stem cell (HSC) niche. First hypothesized by Schofield in 1978, the niche is a specific area in the BM that promotes the maintenance of the HSC [Schofield, 1978]. Early data, based on radiation studies and selective isolation of BM regions, suggested that the niche space might be near the endosteum [Gong, 1978; Schofield, 1978]. In 2001, Nilsson et al. formally demonstrated that injected HSCs, but not more mature progenitors home preferentially to near the endosteal surface [Nilsson, 2001].

The support cell in the niche is the osteoblast. Zhang et al. were able to image the HSC in contact with endosteal osteoblast [Zhang, 2003]. Through conditional inactivation of the BMP (bone morphogenetic protein) receptor, they also demonstrated that the subsequent increase in osteoblasts led to an increased number of HSCs. Similarly, Calvi et al. increased the number of osteoblasts and HSCs by injecting parathyroid hormone (PTH) into mice [Calvi, 2003]. The PTH treatment of mice prior to lethal irradiation also lowered the minimum transplant cell dose for hematopoietic rescue. This important proof-of-principle experiment suggests that stem cell niche quality can be an important factor in HSCT outcomes.

More recently, Czechowicz et al. demonstrated that the niche is saturable at a fixed quantity of HSCs in nonconditioned murine recipients [Czechowicz, 2007]. That is, once 250 HSCs are infused there is only a minimal increase in donor chimerism even at 70-fold higher doses. The authors then "cleared" the niche using a monoclonal antibody to c-kit, which is a receptor on the surface of mouse HSCs. Creating this "space" allowed greater engraftment in these animals. The authors hypothesized that creating greater niche space may allow HSC transplants in humans with less intense conditioning.

Taken together, this data suggests that niche size may be a limiting factor in the setting of HSC transplant. Due to differences in oxygen tension between the fetus and adult, the endosteal niche space may also be less supportive for cord blood than adult HSCs [Dao, 2007]. As such, niche size may be especially limiting in the setting of CBT leading to the unit that is infused first taking up the available HSC space and having an engraftment advantage. In addition, as only a certain percentage of stem cells home correctly to the BM, a higher cell dose would lead to a greater number of cells being able to reach and survive in the niche space. 
The Minnesota group found no relationship between order of infusion or cell dose and cord predominance. This difference might reflect the fact that in those studies the CBU were infused $<1$ apart [Brunstein, 2007]. In our study, as the second unit was not thawed and processed until confirmation of successful infusion of the first unit, 94\% of units were infused $>4 \mathrm{~h}$ apart. The Nilsson study demonstrated that HSCs can home to the endosteal space in under $5 \mathrm{~h}$ [Nilsson, 2001]. The effect of timing of infusion on outcomes from DCBT needs to be further investigated.

There may be clinical consequences of predicting cord predominance. In our study of 38 patients, only the CD34 dose of the winning unit, not the combined dose nor dose of the losing unit, correlated with time to platelets $>100,000(p=0.05)$ with similar trends for ANC $>500$ and platelets $>20,000$ [Haspel, 2007]. This result provides direct evidence that only the winning cord is able to successfully occupy the niche space and only characteristics of this cord can specifically impact long-term engraftment.

This finding also suggests that infusing the CBU with the higher CD34+ cell dose first may lead to that unit predominating and faster recovery of cell counts. In 20 transplants, we infused the CBU with the higher prethaw TNC dose first. In 14 of these transplants (70\%), the unit with higher CD34+ cell dose, based on our postthaw determination, also was infused first. In 10 of these 14 transplants (71\%), the CBU infused first (higher CD34+ cell dose) was predominant [Haspel, 2007]. Consistent with the known poor correlation between collection and transplant center CD34+ cell dose, using the prethaw CD34+ cell dose would have led to the unit with the higher postthaw CD34+ infused first only $65 \%$ of the time [Wagner, 2006]. Our results reflect the imperfect correlation between TNC and CD34+ cell counts and the variability in methods for determining cellular content of products. A method to accurately determine CD34+ cell dose prior to infusion might be beneficial to insure that the unit with the higher dose is infused first. In this way, that unit would be more likely to predominate with subsequent faster engraftment.

\section{ARE TWO CORDS BETTER THAN ONE?}

There is limited data to suggest DCBT is better than single CBT in regard to engraftment. In the largest study, Brunstein et al. compared patients treated with a RIC regimen followed by single or DCBT [Brunstein, 2007]. Although there was no difference in graft failure, the authors do not report the separate median engraftment times for the single versus the DCBTs. While there was a trend for better overall survival with DCBT, there was also a higher rate of acute GVHD, which may be a reflection of greater infused CD3 + cell dose. In agreement with the authors, an accompanying editorial concluded that DCBT "seems likely to emerge as a standard" for CBT in adults [Shpall, 2007]. This statement should be taken cautiously as this trial included only 15 single CBT patients and was not randomized. It is possible that if DCBT recipients were simply infused with the unit with the higher cell dose, similar results would have been obtained.

One might expect stem cell dose would still be an issue with DCBT as bone marrow still has approximately five times the TNC dose of two CBUs. In addition, only a single CBU is often detected by chimerism studies days to weeks prior to ANC and platelet engraftment. Consistent with these facts, we found that only the CD34+ cell dose of the predominant unit actually predicts engraftment.

If a second cord is promoting engraftment or enhancing survival, this benefit is likely not due to HSC support, but perhaps through some other accessory cell mechanism. For 
example, two groups have reported that infusion of mesenchymal cells with $\mathrm{CB}$ in mouse models of CBT leads to improved engraftment [Kim, 2004; Noort, 2002]. Improved survival may also be a reflection of increased numbers of infused T-cells in DCBT leading to a greater graft versus leukemia effect. A randomized trial is needed to determine whether DCBT is truly better than single CBT and is underway in the pediatric population.

\section{OTHER EXPERIMENTAL STRATEGIES}

Other approaches to improve engraftment are being investigated. A Spanish group has attempted coinfusion of adult HSCs with a single CBU in 27 patients receiving an ablative regimen [Magro, 2006]. The adult HSCs were CD34+ cell selected and infused at a median dose of $2.3 \times 10^{6}$ cells $/ \mathrm{kg}$. The majority $(85 \%)$ of the adult HSCs were from haploidentical donors while the remainder were from unrelated donors. The median TNC dose of the CBUs was $2.37 \times 10^{7} / \mathrm{kg}$. Neutrophil engraftment occurred rapidly at a median of 10 days. Engraftment of platelets $>20,000$ and 50,000 occurred at a median of 33 and 57 days, respectively. At the time of engraftment, chimerism studies showed a predominance of hematopoiesis from the adult HSCs. Over time, there was a gradual increase in contribution to hematopoiesis by the CBU such that $93 \%$ of the patients eventually achieved full donor CBU chimerism at a median of 55 days.

Other groups have attempted to expand the HSCs in CBUs ex vivo [Hofmeister, 2007]. Systems generally involve addition of stromal cells and/or cytokines. Patients in human trials, however, have not had faster engraftment possibly due to loss of HSCs during culture. The HSC expansion is further discussed in Chapter 2.

In contrast to increasing the number of infused HSCs, a unique approach to improving outcomes in CBT involves enhancing the ability of cord blood stem cells to engraft. As noted above, PTH has been shown to enhance the HSC niche space and minimize the number of stem cells required to rescue mice following lethal irradiation [Calvi, 2003]. A study is currently underway to determine whether PTH may enhance engraftment in the setting of DCBT. In another approach, North et al. have used prostaglandin E2 to expand HSCs in mouse and zebrafish models. This treatment may also prove useful in cord blood transplants [North, 2007].

\section{SUMMARY}

Cord blood transplant is a viable option for patients with hematologic malignancies. Many clinical and scientific questions remain, however, regarding strategies to improve engraftment and other outcomes. As the only procedure involving perinatal stem cells in widespread clinical use, cord blood transplant serves as a paradigm for new approaches in this area of regenerative medicine.

\section{REFERENCES}

Appelbaum FR. 2007. Hematopoietic-cell transplantation at 50. N Engl J Med. 357:1472-1475.

Ballen KK, Spitzer TR, Yeap BY, McAfee S, Dey BR, Attar E, Haspel R, Kao G, Liney D, Alyea E, Lee S, Cutler C, Ho V, Soiffer R, Antin JH. 2007. Double unrelated reduced-intensity umbilical cord blood transplantation in adults. Biol Blood Marrow Transplant. 13:82-89. 
Barker JN, Weisdorf DJ, Wagner JE. 2001. Creation of a double chimera after the transplantation of umbilical-cord blood from two partially matched unrelated donors. $\mathrm{N}$ Engl $\mathrm{J}$ Med. 344:1870-1871.

Barker JN, Weisdorf DJ, DeFor TE, Blazar BR, Miller JS, Wagner JE. 2003. Rapid and complete donor chimerism in adult recipients of unrelated donor umbilical cord blood transplantation after reducedintensity conditioning. Blood. 102:1915-1919.

Barker JN, Weisdorf DJ, DeFor TE, Blazar BR, McGlave PB, Miller JS, Verfaillie CM, Wagner JE. 2005. Transplantation of 2 partially HLA-matched umbilical cord blood units to enhance engraftment in adults with hematologic malignancy. Blood. 105:1343-1347.

Baron F, Little MT, Storb R. 2005. Kinetics of engraftment following allogeneic hematopoietic cell transplantation with reduced-intensity or nonmyeloablative conditioning. Blood Rev. 19:153-164.

Beam D, Poe MD, Provenzale JM, Szabolcs P, Martin PL, Prasad V, Parikh S, Driscoll T, Mukundan S, Kurtzberg J, Escolar ML. 2007. Outcomes of unrelated umbilical cord blood transplantation for X-linked adrenoleukodystrophy. Biol Blood Marrow Transplant. 13:665-674.

Bensinger WI, Martin PJ, Storer B, Clift R, Forman SJ, Negrin R, Kashyap A, Flowers ME, Lilleby K, Chauncey TR, Storb R, Appelbaum FR. 2001. Transplantation of bone marrow as compared with peripheral-blood cells from HLA-identical relatives in patients with hematologic cancers. N Engl J Med. 344:175-181.

Blaise D, Kuentz M, Fortanier C, Bourhis JH, Milpied N, Sutton L, Jouet JP, Attal M, Bordigoni P, Cahn JY, Boiron JM, Schuller MP, Moatti JP, Michallet M. 2000. Randomized trial of bone marrow versus lenograstim-primed blood cell allogeneic transplantation in patients with early-stage leukemia: A report from the Societe Francaise de Greffe de Moelle. J Clin Oncol. 18:537-546.

Bredeson C, Leger C, Couban S, Simpson D, Huebsch L, Walker I, Shore T, Howson-Jan K, Panzarella T, Messner H, Barnett M, Lipton J. 2004. An evaluation of the donor experience in the Canadian multicenter randomized trial of bone marrow versus peripheral blood allografting. Biol Blood Marrow Transplant. 10:405-414.

Brunstein CG, Barker JN, Weisdorf DJ, DeFor TE, Miller JS, Blazar BR, McGlave PB, Wagner JE. 2007. Umbilical cord blood transplantation after nonmyeloablative conditioning: Impact on transplant outcomes in 110 adults with hematological disease. Blood. 110:3064-3070.

Calvi LM, Adams GB, Weibrecht KW, Weber JM, Olson DP, Knight MC, Martin RP, Schipani E, Divieti P, Bringhurst FR, Milner LA, Kronenberg HM, Scadden DT. 2003. Osteoblastic cells regulate the haematopoietic stem cell niche. Nature (London). 425:841-846.

Center for International Blood Marrow Transplant Research (CIBMTR). 2007. Allogeneic stem cell sources by recipient age 1997-2006. Available at https://campus.mcw.edu/AngelUploads/ Content/CS_IBMTR2/_assoc/ECCBED0AF0A4492BB667FB6227DC7C06/summary05_Pt1_ files/frame.htm. Accessed 1/24/08.

Chen Y-B, Spitzer TR. 2007. Current status of reduced-intensity allogeneic stem cell transplantation using alternative donors. Leukemia. 22:31-41.

Chow R, Nademanee A, Rosenthal J, Karanes C, Jaing TH, Graham ML, Tsukahara E, Wang B, Gjertson D, Tan P, Forman S, Petz LD. 2007. Analysis of hematopoietic cell transplants using plasma-depleted cord blood products that are not red blood cell reduced. Biol Blood Marrow Transplant. 13:1346-1357.

Couban S, Simpson DR, Barnett MJ, Bredeson C, Hubesch L, Howson-Jan K, Shore TB, Walker IR, Browett P, Messner HA, Panzarella T, Lipton JH. 2002. A randomized multicenter comparison of bone marrow and peripheral blood in recipients of matched sibling allogeneic transplants for myeloid malignancies. Blood. 100:1525-1531.

Cutler C, Antin JH. 2004. Sirolimus for GVHD prophylaxis in allogeneic stem cell transplantation. Bone Marrow Transplant. 34:471-476. 
Cutler C, Mitrovitch R, Kao G, Ho V, Alyea E, Koreth J, Armand P, Dey B, Spitzer T, Soiffer R, Antin J, Ballen K. 2007. Double umbilical cord blood transplantation with reduced intensity conditioning and sirolimus-based GVHD prophylaxis. Blood. 118:600a.

Czechowicz A, Kraft D, Weissman IL, Bhattacharya D. 2007. Efficient transplantation via antibodybased clearance of hematopoietic stem cell niches. Science. 318:1296-1299.

Dalle JH, Duval M, Moghrabi A, Wagner E, Vachon MF, Barrette S, Bernstein M, Champagne J, David M, Demers J, Rousseau P, Winikoff R, Champagne MA. 2004. Results of an unrelated transplant search strategy using partially HLA-mismatched cord blood as an immediate alternative to HLA-matched bone marrow. Bone Marrow Transplant. 33:605-611.

Daly A, McAfee S, Dey B, Colby C, Schulte L, Yeap B, Sackstein R, Tarbell NJ, Sachs D, Sykes M, Spitzer TR. 2003. Nonmyeloablative bone marrow transplantation: Infectious complications in 65 recipients of HLA-identical and mismatched transplants. Biol Blood Marrow Transplant. $9: 373-382$.

Dao MA, Creer MH, Nolta JA, Verfaillie CM. 2007. Biology of umbilical cord blood progenitors in bone marrow niches. Blood. 110:74-81.

Delaney M, Yeap B, Haspel RL, Spitzer TR, McAfee SL, Dey B, Attar E, Kao G, Alyea E, Lee S, Cutler C, Ho V, Soiffer RJ, Antin JH, Ballen K. 2007. HLA locus-specific outcomes in double umbilical cord blood reduced intensity transplantation (DCBT) in adults. Blood. 118:605a.

de Lima M, St JL, Wieder ED, Lee MS, McMannis J, Karandish S, Giralt S, Beran M, Couriel D, Korbling M, Bibawi S, Champlin R, Komanduri KV. 2002. Double-chimaerism after transplantation of two human leucocyte antigen mismatched, unrelated cord blood units. Br J Haematol. 119:773-776.

Dey BR, McAfee S, Colby C, Sackstein R, Saidman S, Tarbell N, Sachs DH, Sykes M, Spitzer TR. 2003. Impact of prophylactic donor leukocyte infusions on mixed chimerism, graft-versus-host disease, and antitumor response in patients with advanced hematologic malignancies treated with nonmyeloablative conditioning and allogeneic bone marrow transplantation. Biol Blood Marrow Transplant. 9:320-329.

Eapen M, Rubinstein P, Zhang MJ, Stevens C, Kurtzberg J, Scaradavou A, Loberiza FR, Champlin RE, Klein JP, Horowitz MM, Wagner JE. 2007. Outcomes of transplantation of unrelated donor umbilical cord blood and bone marrow in children with acute leukaemia: A comparison study. Lancet. 369:1947-1954.

Favre G, Beksac M, Bacigalupo A, Ruutu T, Nagler A, Gluckman E, Russell N, Apperley J, Szer J, Bradstock K, Buzyn A, Matcham J, Gratwohl A, Schmitz N. 2003. Differences between graft product and donor side effects following bone marrow or stem cell donation. Bone Marrow Transplant. 32:873-880.

Food and Drug Administration (FDA). 2006. Draft Guidance for Industry: Minimally Manipulated, Unrelated, Allogeneic Placental/Umbilical Cord Blood Intended for Hematopoietic Reconstitution in Patients with Hematological Malignancies. Available at http://www.fda.gov/ cber/gdlns/cordbld.pdf. Accessed 1/24/08.

Gluckman E, Broxmeyer HA, Auerbach AD, Friedman HS, Douglas GW, Devergie A, Esperou H, Thierry D, Socie G, Lehn P. 1989. Hematopoietic reconstitution in a patient with Fanconi's anemia by means of umbilical-cord blood from an HLA-identical sibling. $\mathrm{N}$ Engl $\mathrm{J}$ Med. 321:1174-1178.

Gluckman E. 2000. Current status of cord blood hematopoietic stem cell transplantation. Exp Hematol. 28:1197-1205.

Gong JK. 1978. Endosteal marrow: A rich source of hematopoietic stem cells. Science. 199:1443-1445.

Government Accounting Office (GAO). 2002. Bone Marrow Transplants. Available at http://www. gao.gov/new.items/d03182.pdf. Accessed 1/24/08. 
Hahn T, Bunworasate U, George MC, Bir AS, Chinratanalab W, Alam AR, Bambach B, Baer MR, Slack JL, Wetzler M, Becker JL, McCarthy PL, Jr. 2003. Use of nonvolume-reduced (unmanipulated after thawing) umbilical cord blood stem cells for allogeneic transplantation results in safe engraftment. Bone Marrow Transplant. 32:145-150.

Haspel R, Kao G, Yeap BY, Cutler C, Soiffer RJ, Alyea EP, Ho VT, Koreth J, Dey BR, McAfee SL, Attar EC, Spitzer T, Antin JH, Ballen KK. 2007. Preinfusion variables predict the predominant unit in the setting of reduced-intensity double cord blood transplantation. Bone Marrow Transplant. Advance online publication November 26.

Heldal D, Brinch L, Tjonnfjord G, Solheim BG, Egeland T, Gadeholt G, Albrechtsen D, Aamodt G, Evensen SA. 2002. Donation of stem cells from blood or bone marrow: Results of a randomised study of safety and complaints. Bone Marrow Transplant. 29:479-486.

Hofmeister CC, Zhang J, Knight KL, Le P, Stiff PJ. 2007. Ex vivo expansion of umbilical cord blood stem cells for transplantation: Growing knowledge from the hematopoietic niche. Bone Marrow Transplant. 39:11-23.

Horowitz MM, Confer DL. 2005. Evaluation of hematopoietic stem cell donors. Am Soc Hematol Educ Program. 469-475.

Jaing TH, Hung IJ, Yang CP, Chen SH, Sun CF, Chow R. 2005. Rapid and complete donor chimerism after unrelated mismatched cord blood transplantation in 5 children with beta-thalassemia major. Biol Blood Marrow Transplant. 11:349-353.

Kamani N, Spellman S, Hurley CK, Barker JN, Smith FO, Oudshoorn M, Bray R, Smith A, Williams TM, Logan B, Eapen M, Anasetti C, Setterholm M, Confer DL. 2008. State of the art review: HLA matching and outcome of unrelated donor umbilical cord blood transplants. Biol Blood Marrow Transplant. 14:1-6.

Kim DW, Chung YJ, Kim TG, Kim YL, Oh IH. 2004. Cotransplantation of third-party mesenchymal stromal cells can alleviate single-donor predominance and increase engraftment from double cord transplantation. Blood. 103:1941-1948.

Kogler G, Enczmann J, Rocha V, Gluckman E, Wernet P. 2005. High-resolution HLA typing by sequencing for HLA-A, -B, -C, -DR, -DQ in 122 unrelated cord blood/patient pair transplants hardly improves long-term clinical outcome. Bone Marrow Transplant. 36:1033-1041.

Kolb HJ, Mittermuller J, Clemm C, Holler E, Ledderose G, Brehm G, Heim M, Wilmanns W. 1990. Donor leukocyte transfusions for treatment of recurrent chronic myelogenous leukemia in marrow transplant patients. Blood. 76:2462-2465.

Laroche V, McKenna DH, Moroff G, Schierman T, Kadidlo D, McCullough J. 2005. Cell loss and recovery in umbilical cord blood processing: A comparison of postthaw and postwash samples. Transfusion. 45:1909-1916.

Laughlin MJ, Eapen M, Rubinstein P, Wagner JE, Zhang MJ, Champlin RE, Stevens C, Barker JN, Gale RP, Lazarus HM, Marks DI, van Rood JJ, Scaradavou A, Horowitz MM. 2004. Outcomes after transplantation of cord blood or bone marrow from unrelated donors in adults with leukemia. N Engl J Med. 351:2265-2275.

Magro E, Regidor C, Cabrera R, Sanjuan I, Fores R, Garcia-Marco JA, Ruiz E, Gil S, Bautista G, Millan I, Madrigal A, Fernandez MN. 2006. Early hematopoietic recovery after single unit unrelated cord blood transplantation in adults supported by co-infusion of mobilized stem cells from a third party donor. Haematologica. 91:640-648.

Majhail NS, Brunstein CG, Wagner JE. 2006a. Double umbilical cord blood transplantation. Curr Opin Immunol. 18:571-575.

Majhail NS, Weisdorf DJ, Wagner JE, DeFor TE, Brunstein CG, Burns LJ. 2006b. Comparable results of umbilical cord blood and HLA-matched sibling donor hematopoietic stem cell transplantation after reduced-intensity preparative regimen for advanced Hodgkin lymphoma. Blood. 107:3804-3807. 
Nagamura-Inoue T, Shioya M, Sugo M, Cui Y, Takahashi A, Tomita S, Zheng Y, Takada K, Kodo H, Asano S, Takahashi TA. 2003. Wash-out of DMSO does not improve the speed of engraftment of cord blood transplantation: Follow-up of 46 adult patients with units shipped from a single cord blood bank. Transfusion. 43:1285-1295.

Netcord. 2007. Inventory and Use November. Available at https://www.netcord.org/inventory.html. Accessed 1/24/08.

Nilsson SK, Johnston HM, Coverdale JA. 2001. Spatial localization of transplanted hemopoietic stem cells: Inferences for the localization of stem cell niches. Blood. 97:2293-2299.

Noort WA, Kruisselbrink AB, in't Anker PS, Kruger M, van Bezooijen RL, de Paus RA, Heemskerk MH, Lowik CW, Falkenburg JH, Willemze R, Fibbe WE. 2002. Mesenchymal stem cells promote engraftment of human umbilical cord blood-derived CD34(+) cells in NOD/SCID mice. Exp Hematol. 30:870-878.

North TE, Goessling W, Walkley CR, Lengerke C, Kopani KR, Lord AM, Weber GJ, Bowman TV, Jang IH, Grosser T, FitzGerald GA, Daley GQ, Orkin SH, Zon LI. 2007. Prostaglandin E2 regulates vertebrate haematopoietic stem cell homeostasis. Nature (London). 447:1007-1011.

Rocha V, Cornish J, Sievers EL, Filipovich A, Locatelli F, Peters C, Remberger M, Michel G, Arcese W, Dallorso S, Tiedemann K, Busca A, Chan KW, Kato S, Ortega J, Vowels M, Zander A, Souillet G, Oakill A, Woolfrey A, Pay AL, Green A, Garnier F, Ionescu I, Wernet P, Sirchia G, Rubinstein P, Chevret S, Gluckman E. 2001. Comparison of outcomes of unrelated bone marrow and umbilical cord blood transplants in children with acute leukemia. Blood. 97:2962-2971.

Rocha V, Labopin M, Sanz G, Arcese W, Schwerdtfeger R, Bosi A, Jacobsen N, Ruutu T, de LM, Finke J, Frassoni F, Gluckman E. 2004. Transplants of umbilical-cord blood or bone marrow from unrelated donors in adults with acute leukemia. N Engl J Med. 351:2276-2285.

Rowley SD, Donaldson G, Lilleby K, Bensinger WI, Appelbaum FR. 2001. Experiences of donors enrolled in a randomized study of allogeneic bone marrow or peripheral blood stem cell transplantation. Blood. 97:2541-2548.

Sanz MA. 2004. Cord-blood transplantation in patients with leukemia—a real alternative for adults. N Engl J Med. 351:2328-2330.

Schmitz N, Beksac M, Hasenclever D, Bacigalupo A, Ruutu T, Nagler A, Gluckman E, Russell N, Apperley JF, Gorin NC, Szer J, Bradstock K, Buzyn A, Clark P, Borkett K, Gratwohl A. 2002. Transplantation of mobilized peripheral blood cells to HLA-identical siblings with standard-risk leukemia. Blood. 100:761-767.

Schofield R. 1978. The relationship between the spleen colony-forming cell and the haemopoietic stem cell. Blood Cells. 4:7-25.

Shpall EJ, de Lima M, Jones R, Champlin R. 2007. Are 2 cords better than 1? Blood. 110:2789-2790.

Staba SL, Escolar ML, Poe M, Kim Y, Martin PL, Szabolcs P, lison-Thacker J, Wood S, Wenger DA, Rubinstein P, Hopwood JJ, Krivit W, Kurtzberg J. 2004. Cord-blood transplants from unrelated donors in patients with Hurler's syndrome. N Engl J Med. 350:1960-1969.

Stevens CE, Scaradavou A, Carrier C, Carpenter C, Rubinstein P. 2005. An Empirical Analysis of the Probability of Finding a Well Matched Cord Blood Unit: Implications for a National Cord Blood Inventory. Blood. 106:579a.

Takahashi S, Iseki T, Ooi J, Tomonari A, Takasugi K, Shimohakamada Y, Yamada T, Uchimaru K, Tojo A, Shirafuji N, Kodo H, Tani K, Takahashi T, Yamaguchi T, Asano S. 2004. Single-institute comparative analysis of unrelated bone marrow transplantation and cord blood transplantation for adult patients with hematologic malignancies. Blood. 104:3813-3820.

Takahashi S, Ooi J, Tomonari A, Konuma T, Tsukada N, Oiwa-Monna M, Fukuno K, Uchiyama M, Takasugi K, Iseki T, Tojo A, Yamaguchi T, Asano S. 2007. Comparative single-institute analysis of cord blood transplantation from unrelated donors with bone marrow or peripheral blood stem-cell transplants from related donors in adult patients with hematologic malignancies after myeloablative conditioning regimen. Blood. 109:1322-1330. 
Wagner E, Duval M, Dalle JH, Morin H, Bizier S, Champagne J, Champagne MA. 2006. Assessment of cord blood unit characteristics on the day of transplant: Comparison with data issued by cord blood banks. Transfusion. 46:1190-1198.

Wagner JE, Barker JN, DeFor TE, Barker S, Blazar BR, Eide C, Goldman A, Kersey J, Krivit W, MacMillan ML, Orchard PJ, Peters C, Weisdor DJ, Ramsay NKC, Davies SM. 2002. Transplantation of unrelated donor umbilical cord blood in 102 patients with malignant and nonmalignant diseases: Influence of CD34 cell dose and HLA disparity on treatment-related mortality and survival. Blood. 100:1611-1618.

Zhang J, Niu C, Ye L, Huang H, He X, Tong WG, Ross J, Haug J, Johnson T, Feng JQ, Harris S, Wiedemann LM, Mishina Y, Li L. 2003. Identification of the haematopoietic stem cell niche and control of the niche size. Nature (London). 425:836-841. 
